\title{
Utility of Microwave Radiometry for Diagnostic and Therapeutic Applications of Non-Invasive Temperature Monitoring
}

\author{
Paul R. Stauffer \\ Thomas Jefferson University \\ Dario B. Rodrigues \\ Thomas Jefferson University \\ Paolo F. Maccarini \\ Duke University
}

Follow this and additional works at: https://jdc.jefferson.edu/radoncfp

Part of the Radiology Commons

\section{Let us know how access to this document benefits you}

\section{Recommended Citation \\ 2014 IEEE Benjamin Franklin Symposium on Microwave and Antenna Sub-systems}

This Article is brought to you for free and open access by the Jefferson Digital Commons. The Jefferson Digital Commons is a service of Thomas Jefferson University's Center for Teaching and Learning (CTL). The Commons is a showcase for Jefferson books and journals, peer-reviewed scholarly publications, unique historical collections from the University archives, and teaching tools. The Jefferson Digital Commons allows researchers and interested readers anywhere in the world to learn about and keep up to date with Jefferson scholarship. This article has been accepted for inclusion in Department of Radiation Oncology Faculty Papers by an authorized administrator of the Jefferson Digital Commons. For more information, please contact: JeffersonDigitalCommons@jefferson.edu. 


\title{
Utility of Microwave Radiometry for Diagnostic and Therapeutic Applications of Non-Invasive Temperature Monitoring
}

\author{
Paul R. Stauffer ${ }^{\mathrm{a}}$, Dario B. Rodrigues ${ }^{\mathrm{a}}$, and Paolo F. Maccarini ${ }^{\mathrm{b}}$ \\ ${ }^{a}$ Radiation Oncology Dept., Thomas Jefferson University, Philadelphia PA USA 19107, \\ ${ }^{\mathrm{b}}$ Biomedical Engineering Dept., Duke University, Durham NC USA 27705
}

\begin{abstract}
This paper describes the use of microwave radiometry for several diagnostic and therapeutic applications that can benefit from accurate non-invasive measurement of volume average temperature of tissue regions extending $4 \mathrm{~cm}$ or more into the body. Design features are summarized for an appropriate high sensitivity long term stable system with $\mathbf{2 . 5}$ and $7 \mathrm{~cm}$ diameter receive antennas and integral $1.35 \mathrm{GHz}$ total power radiometer electronics. Radiometer performance is characterized with electromagnetic and thermal simulations and experimental measurements in realistic models of two typical clinical applications. Results demonstrate sufficient sensitivity to track clinically significant changes in temperature of deep tissue targets for applications like the non-invasive detection of vesicoureteral reflux and monitoring brain "core" temperature during extended hypothermic surgery.
\end{abstract}

Index Terms - Microwave radiometry, thermal sensors, microstrip antennas, biomedical telemetry.

\section{INTRODUCTION}

There are numerous diagnostic and therapeutic applications for non-invasive monitoring of deep tissue temperature. Potential high impact diagnostic applications include: i) early detection of breast cancer by probing for small regions of elevated temperature to distinguish benign calcification from aggressive tumor growth [1]; ii) monitoring of critical deep brain temperature during extended hypothermic surgery or following severe head trauma $[2,3]$; iii) long term monitoring of brown adipose tissue (BAT) to assess effect of interventions that stimulate BAT metabolism for control of obesity and diabetes $[4,5]$; and iv) monitoring of rheumatoid arthritis following treatments for reduction of inflammation. Many other diagnostic applications are poised to benefit from reliable non-invasive deep temperature measurement, such as monitoring of muscular exercise in rehabilitation medicine, assessment of therapeutic interventions for spinal cord injury, thyroid disease, and tissue changes after radiation and/or chemotherapy.

There are also potentially high impact therapeutic applications for safe and effective non-invasive radiometry such as: i) tumor temperature monitoring for realtime feedback control of hyperthermia therapy for cancer [6-9], and ii) feedback control of warming bladder urine as stimulus for radiometric detection of temperature rise in kidneys when diagnosing vesicoureteral reflux (VUR) in children $[10,11]$.
This report describes the use of passive microwave radiometry for non-invasive thermal sensing of tissue targets located moderately deep in the body using a miniature microwave antenna sensor to be held securely in place on the skin under an elastic strap. With continued miniaturization of the sensor, this approach should be suitable for new clinical applications that benefit from fixation of the sensor under a thin adhesive patch. The following sections briefly describe the current radiometer sensor and readout electronics, electromagnetic and thermal simulations of possible sense regions, phantom models used to evaluate the system, and radiometer performance in terms of accuracy and long term stability of deep tissue sensing in two representative tissue monitoring applications.

\section{RADIOMETRY SYSTEM}

The basic configuration of our high-sensitivity $500 \mathrm{MHz}$ bandwidth $1.35 \mathrm{GHz}$ center frequency microwave radiometry system is shown in Fig.1. Several configurations of radiometer electronics have evolved and specifics will be published elsewhere. The common goal has been to provide maximum sensitivity by placing a high gain low noise amplifier immediately adjacent to the receive antenna to eliminate EMI pickup and interconnection losses. The circuit also provides continuous reading of signal from tissue while providing calibration to known temperature references through parallel rather than time-sequenced amplification, using dual matched amplifier first stage.[12] The radiometer consists of four components: i) a miniature skin contacting sensor with receive antenna and printed circuit with temperature references, RF switches, filters and first amplification stage $(+15 \mathrm{db})$ to raise the extremely small signal from tissue above environmental noise, ii) electronics chassis with second stage amplification $(+40 \mathrm{db})$, more filtering, and conversion to a digital signal proportional to received power, iii) computer display with signal processing software for temporal averaging, drift correction, and calibration of the algorithm converting received power to equivalent tissue temperature, and iv) $12 \mathrm{~V}$ battery.

The tissue contacting radiometric sensor integrates the critical first amplification stage and preliminary signal filtering onto a miniature printed circuit that is mounted on the back side of a high directivity receive antenna, both encased in EMI-shielding that seals to lossy tissue surface 
around the sensor perimeter. A thick substrate log spiral microstrip antenna was designed with HFSS (Ansys Corp) for maximum penetration into various target tissues. Optimization parameters included the number and winding of spiral turns, and thickness and dielectric properties of the substrate and matching layer. A $7 \mathrm{~cm}$ tapered log spiral was determined most appropriate for recording temperature rise in kidney located $3-5 \mathrm{~cm}$ below the skin [13, 14], and a $2.6 \mathrm{~cm}$ diameter tapered $\log$ spiral was found to maximize coupling through the human skull into brain.[15]

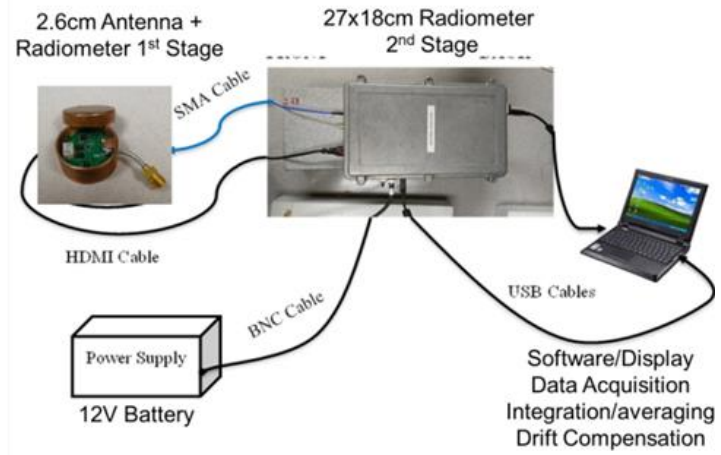

Fig. 1 Basic configuration of high-sensitivity microwave radiometry system.

\section{RADIOMETER PERFORMANCE}

Performance of the radiometry system is characterized in both simulated and experimental multilayer phantom models of two representative clinical measurement sites: A) human brain underlying intact scalp and skull, and B) kidney located $3-5 \mathrm{~cm}$ deep in the torso. In each case, the experimental models include layers of circulating tissuemimicking liquids controlled at different temperatures to characterize our ability to quantify small changes in target temperature at depth under normothermic surface tissues.
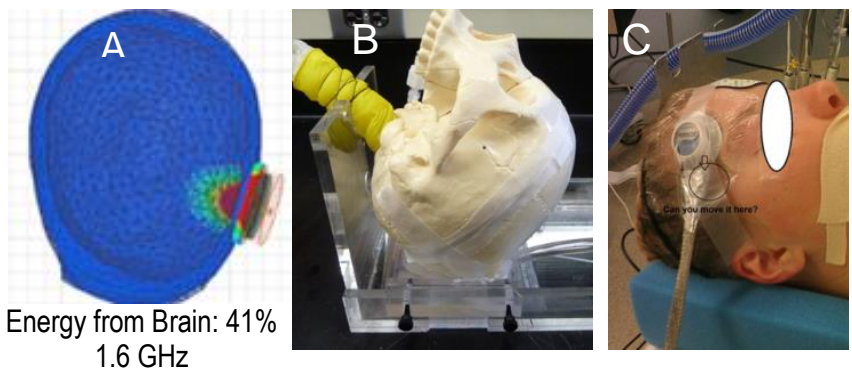

Fig. 2 A) HFSS-simulated receive pattern at $1.6 \mathrm{GHz}$ for a $2.5 \mathrm{~cm}$ log spiral antenna on B) multilayer head model with temperaturecontrolled circulating scalp and brain tissue compartments. C) IRB approved brain temperature monitoring of patient during surgery.

\section{A. Monitoring Brain "Core” Temperature}

As simulated with Ansys HFSS, Fig. 2A shows the SAR pattern at $1.6 \mathrm{GHz}$ of a high directivity $2.6 \mathrm{~cm}$ dia thick substrate tapered log spiral microstrip antenna in the layered head model of Fig. 2B. While the highest power deposition rate occurs in the thin superficial scalp layer, the simulations demonstrate minimal power deposition (and received energy) from low electrical conductivity skull bone and a significant percentage of total signal (41\%) received from brain. In practice, the radiometer collects a signal integrated from all tissue that is a weighted average of SAR patterns of all frequencies within the sensing band (1.1-1.6 GHz).
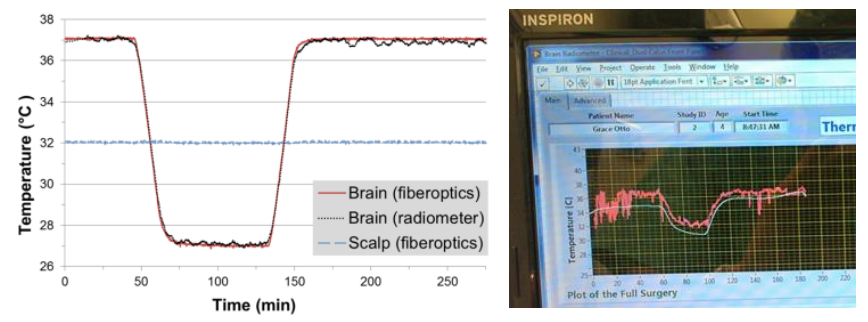

Fig. 3 A) Radiometric signal (black) and fiberoptic measured brain temperature agree within $0.4^{\circ} \mathrm{C}$ over 4 hour experiment with Fig.2B model. B) Close correlation of core temperature measures from brain radiometer (red) and nasopharyngeal (white) while monitoring Fig. 2C patient during two hour hypothermic surgery.

\section{B. Detection of Vesicoureteral Reflux}

Our team is investigating a non-invasive approach to detecting VUR that minimizes trauma by eliminating the Foley catheter.[10, 11, 13] This application requires radiometric monitoring of temperature rise in kidney while controlling MW heating of bladder urine with radiometry.

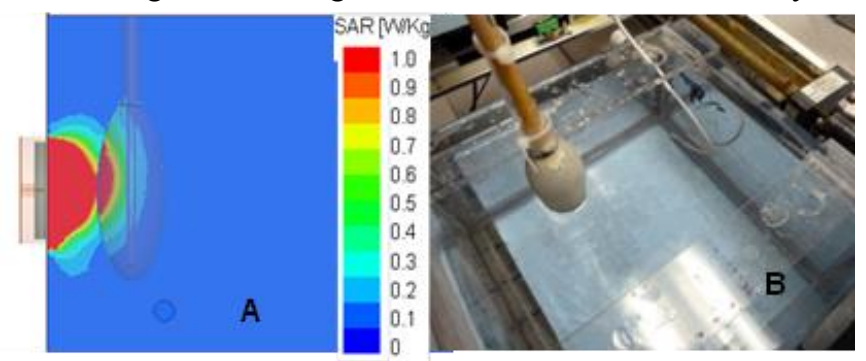

Fig. 4 A) HFSS simulation of receive pattern of $5 \mathrm{~cm} \log$ spiral looking through Mylar window into the muscle-kidney phantom, showing significant received energy (red) from within the "kidney" $3-5 \mathrm{~cm}$ deep in muscle. B) Photo of experimental model with temperature-controlled "kidney" at $3-5 \mathrm{~cm}$ depth in circulating muscle-equivalent phantom at separately controlled temperature.

To test our ability to detect elevated kidney temperature underlying normothermic fat and muscle, a phantom model was constructed from $25 \times 25 \times 15 \mathrm{~cm}$ Plexiglas container filled with circulating $35^{\circ} \mathrm{C}$ liquid "muscle" surrounding a saline filled latex balloon "kidney" (Fig.4). The "kidney" was positioned at variable distance $(1-5 \mathrm{~cm})$ from a $7 \mathrm{~cm}$ dia. radiometric antenna contacting a 0.010 " thick Mylar film on one side of box. "Kidney" temperature was varied to produce a range of surface/deep temperature gradients to determine radiometer sensitivity as a function of target volume, depth, and temperature difference to surrounding muscle. Radiometer measurements during a transient 3.5 or $5^{\circ} \mathrm{C}$ increase of kidney temperature are shown in Fig. 5 . 

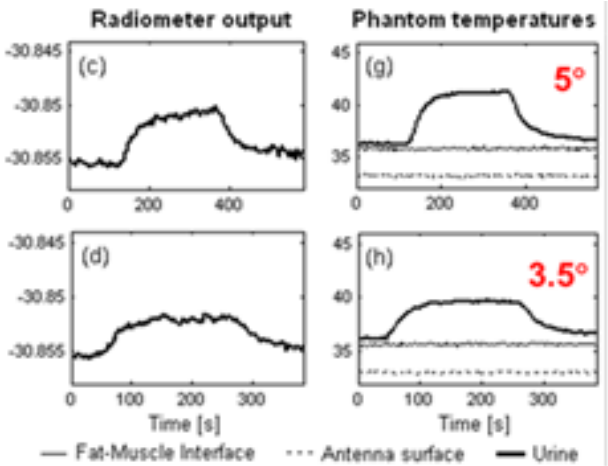

$$
\text { - Fat-Muscle interdace }
$$

Fig. 5 Left panels show radiometric received power as a function of time measured in the Fig. 4B kidney phantom when the saline circulating inside the $30 \mathrm{ml}$ balloon was raised either 3.5 or $5^{\circ} \mathrm{C}$ above the surrounding $35^{\circ} \mathrm{C}$ "muscle", as measured with a fiberoptic sensor (right panels) inside the balloon.

\section{CONCLUSION}

This paper briefly describes a 1.1-1.6 GHz single band radiometry system for measuring volume average temperature of tissue targets at moderate depth in the body. Computer modeling and experimental phantom model tests are described for two typical clinical applications for this technology. Current software with temporal averaging and drift correction provides a stable radiometric signal for accurate monitoring of temperature to at least $5 \mathrm{~cm}$ depth. These results demonstrate that passive microwave radiometry is now poised to emerge as an accurate and affordable noninvasive thermometry approach for many applications in monitoring subsurface tissue temperature.

\section{ACKNOWLEDGEMENTS}

The authors wish to acknowledge support from NIH R21DK092912 and R43/44RR14940 which helped develop and test the radiometer for several clinical applications. We would like to recognize significant contributions from a diverse team of collaborators originating from the University of Tromso, University of Utah, University of Rome Tor Vergata, University of L'Aquila, and the commercial support from Thermimage Corporation.

\section{REFERENCES}

[1] J. Shaeffer, A.M. El-Mahdi and K.L. Carr, Cancer detection studies using a 4.7 gigahertz radiometer. Cancer Detect Prev. 4(1-4): 571-8, 1981.

[2] P.R. Stauffer, B.W. Snow, D.B. Rodrigues, S. Salahi, T.R. Oliveira, D. Reudink and P.F. Maccarini, Non-invasive measurement of brain temperature with microwave radiometry: Demonstration in a head phantom and clinical case. Neuroradiol J. 27(1): 3-12, 2014.

[3] J.W. Hand, G.M.J. Van Leeuwen, S. Mizushina, J.B. Van De Kamer, K. Maruyama, T. Sugiura, D.V. Azzopardi and A.D. Edwards, Monitoring of deep brain temperature in infants using multi-frequency microwave radiometry and thermal modelling. Phys. in Med. and Biol.. 46(7): 1885-903, 2001.

[4] D. Rodrigues, P. Maccarini, S. Salahi, E. Colebeck, E. Topsakal, P. Pereira, P. Limao-Vieira and P. Stauffer. Numerical 3d modeling of heat transfer in human tissues for microwave radiometry monitoring of brown fat metabolism. in Proc SPIE: SPIE Press 8584:OS1-12, 2013 PMC3824263.

[5] P.R. Stauffer, D.B. Rodriques, S. Salahi, E. Topsakal, T.R. Oliveira, A. Prakash, F. D'Isidoro, D. Reudink, B.W. Snow and P.F. Maccarini, Stable microwave radiometry system for long term monitoring of deep tissue temperature. Proc SPIE. SPIE Press, Vol.8584, 2013.

[6] L. Dubois, J.P. Sozanski, V. Tessier, J.C. Camart, J.J. Fabre, J. Pribetich and M. Chive, Temperature control and thermal dosimetry by microwave radiometry in hyperthermia. Ieee Trans on Mic Theory Techniques. 44(10, pt2): 1755-61, 1996.

[7] S. Jacobsen, P.R. Stauffer and D.G. Neuman, Dual-mode antenna design for microwave heating and noninvasive thermometry of superficial tissue disease. IEEE Transactions on Biomedical Engineering. 47(11): 1500-9, 2000.

[8] S. Jacobsen and P.R. Stauffer, Can we settle with single-band radiometric temperature monitoring during hyperthermia treatment of chestwall recurrence of breast cancer using a dual-mode transceiving applicator? Phys Med Biol. 52(4): 911-28, 2007.

[9] P.R. Stauffer, P. Maccarini, K. Arunachalam, O. Craciunescu, C. Diederich, T. Juang, F. Rossetto, J. Schlorff, A. Milligan, J. Hsu, P. Sneed and Z. Vujaskovic, Conformal microwave array (CMA) applicators for hyperthermia of diffuse chest wall recurrence. Int J Hyperthermia. 26(7): 686-98, 2010.

[10] B.W. Snow, K. Arunachalam, V. De Luca, P.F. Maccarini, O. Klemetsen, Y. Birkelund, T.J. Pysher and P.R. Stauffer, Noninvasive vesicoureteral reflux detection: Heating risk studies for a new device. Journal of Pediatric Urology. 7(6): 624-30, 2011.

[11] P.R. Stauffer, P.F. Maccarini, K. Arunachalam, V. De Luca, S. Salahi, A. Boico, O. Klemetsen, Y. Birkelund, S.K. Jacobsen, F. Bardati, P. Tognolatti and B. Snow, Microwave radiometry for non-invasive detection of vesicoureteral reflux (vur) following bladder warming. Proc SPIE. 7901: 7901OV$1-11,2011$.

[12] O. Klemetsen, Y. Birkelund, S.K. Jacobsen, P.F. Maccarini and P.R. Stauffer, Design of medical radiometer front-end for improved performance. Prog Electromagn Res B Pier B. 27: 289-306, 2011.

[13] K. Arunachalam, P.F. Maccarini, V. De Luca, F. Bardati, B.W. Snow and P.R. Stauffer, Modeling the detectability of vesicoureteral reflux using microwave radiometry. Phys Med Biol. 55(18): 5417-35, 2010.

[14] K. Arunachalam, P. Maccarini, V. De Luca, P. Tognolatti, F. Bardati, B. Snow and P. Stauffer, Detection of vesicoureteral reflux using microwave radiometry-system characterization with tissue phantoms. IEEE Trans Biomed Eng. 58(6): 162936, 2011.

[15] D. Rodrigues, P. Maccarini, S. Salahi, T. Oliveira, P. Pereira, P. Limao-Vieira, B. Snow, D. Reudink and P. Stauffer, Design and optimization of an ultra-wideband and compact microwave antenna for radiometric monitoring of brain temperature. IEEE Trans on Biomed Eng. In Press. 